\title{
Editor's Introduction: Visions, Opportunities and Reflections
}

\author{
Lawrence T. Nichols ${ }^{1}$
}

Published online: 18 February 2016

(C) Springer Science+Business Media New York 2016

We begin with a discussion of public sociology by Herbert Gans, who was among the very first to raise this issue, decades ago. In contrast to many recent analyses that responded to Michael Burawoy's famous 2004 presidential address to the American Sociological Association, Gans looks beyond the profession itself to the audiences that sociologists seek to engage, audiences that he believes we need to understand more fully.

The next three articles deal with emergent issues involving natural science, digital technologies and new methodologies. Daniel McFarland, Amir Goldberg and Kevin Lewis examine the challenges and opportunities that "big data" offers to sociology, including both potentially richer ethnographies and the danger of being colonized by hard, quantitative sciences. Paul Tibbetts then delineates an emergent dialogue between sociology and neuroscience, an issue that goes beyond many, perhaps most, self-definitions of the field found in introductory textbooks. Daniel Burton Shank then builds a case for incorporating new digital technologies into sociological research, with a particular focus on the "Mechanical Turk" offered by Amazon for "crowdsourcing."

Milan Zafirovksi next examines the emergent relations between the fields of sociology and economics, a topic on which he has made important contributions for many years, including articles in this journal. Moving beyond his earlier critiques, Zafirovski advocates the development of a new field of socio-economics.

Roman Abramov contributes an analysis that adds to the growing body of work in this journal about the state of sociology in Russia. His focus is occupations and professions, and he provides a dual narrative that includes both a sketch of the changing landscape of work and also a discussion of how sociologists in the former Soviet Union — often under serious political constraints — examined this landscape, and how their successors in contemporary Russia are studying it more fully.

Lawrence T. Nichols

1nichol2@wvu.edu

1 Morgantown, WV, USA 
Cary $\mathrm{Wu}$ next offers a thoughtful reflection on the longstanding field of urban sociology, an area that rose to prominence in the "golden age" of Chicago sociology through the Jane Addams circle of "settlement sociologists," as well as via Robert Park and his students of urban ecology. Wu is especially concerned that urban sociology has been losing its intellectual identity in recent decades, and she argues for a new approach that focuses on the phenomenon of cities as such, rather than on cities as mere sites for processes studied by other sociological subfields.

Chris Martin's concluding essay expresses a widely shared concern that the increasing dominance of ideologies - especially political doctrines - has had serious negative consequences for sociology. Very much in the spirit of Robert Merton's "ethos of science," he argues against the reduction of the field to politics, where the answers to all important questions are determined in advance, rather than discovered.

I believe that this is a very rich issue, and one that should appeal to a diverse range of colleagues. Sociology must always strive to reinvent itself, while remaining true to its core principles, through creative initiatives. The authors here have succeeded in conveying a sense of new and exciting possibilities, and they have delineated some of the forms in which these might appear. They have captured what I have elsewhere referred to as "living traditions and creative beginnings," which are keys to maintaining a vibrant and viable field. 